\title{
Effects of Rivastigmine on Memory and Cognition in Multiple Sclerosis
}

\author{
Vahid Shaygannejad, Mohsen Janghorbani, Fereshteh Ashtari, \\ Hamid Afshar Zanjani, Naser Zakizade
}

\begin{abstract}
Background: Cognitive dysfunction is one of the common clinical symptoms in multiple sclerosis (MS), but there is no effective treatment for it. Objective: The aim of this study was to evaluate the effect of rivastigmine in treating memory and cognitive dysfunction in MS. Methods: A single-center double-blind placebo-controlled randomized clinical trial conducted from October 2005 to February 2007. Sixty definite MS patients with cognitive impairment age 16 to 54 years were randomly allocated to receive a 12week treatment course of either rivastigmine (1.5 mg once a day increment over 4 weeks to $3 \mathrm{mg}$ twice daily) or placebo. Response to treatment was assessed by the Wechsler Memory Scale (WMS) at baseline and 12 weeks after start of therapy. Results: A slight, but significant memory improvement occurred in both groups. Of the 30 patients treated with rivastigmine, the mean (SD) WMS general memory score increased from 60.3 (4.2) at baseline to 64.9 (5.3) at the end of study period $(\mathrm{P}<0.001)$. Correspondingly, in the 30 patients treated with placebo, the mean (SD) WMS general memory score increased from $60.5(4.9)$ to 64.5 (3.7) (P< 0.001$)$. The average WMS general memory score at the end of trial did not changed between rivastigmine and placebo group (mean difference, 0.4 ; 95\% CI, -2.0, 2.8). Conclusion: No significant differences were seen between rivastigmine and placebo on the mean (SD) WMS general memory score. A larger multicenter study of rivastigmine in MS is warranted in order to more definitely assess the efficacy of this intervention.
\end{abstract}

RÉSUMÉ: Effets de la rivastigmine sur la mémoire et la cognition dans la sclérose en plaques. Contexte : La dysfonction cognitive est l'un des symptômes cliniques fréquents dans la sclérose en plaques (SEP), pour lequel il n'existe aucun traitement efficace. Objectif : Le but de cette étude était d'évaluer l'effet de la rivastigmine dans le traitement de la dysfonction mnésique et cognitive de la SEP. Méthodes : Nous avons effectué un essai clinique randomisé à double insu, contrôlé par placebo, dans un seul centre entre octobre 2005 et février 2007. Soixante patients atteints de SEP certaine avec atteinte cognitive, âgés de 16 à 54 ans, ont été randomisés à recevoir un traitement par la rivastigmine (1,5 mg une fois par jour avec augmentation progressive de la dose sur une période de 4 semaines jusqu'à une dose de $3 \mathrm{mg}$ deux fois par jour) ou un placebo pendant 12 semaines. Le Wechsler Memory Scale (WMS) utilisé en début d'étude et après 12 semaines de traitement a servi à évaluer la réponse au traitement. Résultats : Une amélioration a été observée dans les deux groupes. Cette amélioration, bien que légère, était significative. Chez les 30 patients sous rivastigmine, le score général moyen pour la mémoire au WMS est passé de 60,3 (ÉT 4,2) avant traitement à 64,9 (ÉT 5,3) à la fin de la période de traitement (p <0,01). Chez les 30 patients sous placebo, le score général moyen pour la mémoire au WMS est passé de 60,5 (4,9) à 64,5 (ÉT 3,7) (p < 0,001). La moyenne du score général pour la mémoire au WMS à la fin de l'étude n'avait pas changé significativement entre les deux groupes (différence moyenne 0,4 ; IC à 95\% : -2,0 à 2,8). Conclusion : Aucune différence significative du score général pour la mémoire au WMS n'a été observée entre les patients qui ont reçu la rivastigmine et ceux qui ont reçu le placebo. Une étude multicentres de plus grande envergure sur l'utilité de la rivastigmine dans la SEP est justifiée, afin d'évaluer de façon définitive l'efficacité de cette intervention.

Can. J. Neurol. Sci. 2008; 35: 476-481

Cognitive dysfunction with prominent involvement of memory, sustained attention, executive functions, and information processing speed is a prevalent disabling neuropsychologic symptom of multiple sclerosis (MS) with prevalence of $40-65 \% .{ }^{1}$ It is associated with significant disability and impaired quality of life, adversely affecting daily activity and role fulfillment in work and social life, independently from physical disability, ${ }^{2-4}$ with profound socioeconomic consequences. Cognitively impaired MS patients experience higher rate of unemployment, ${ }^{4-6}$ and divorce ${ }^{5}$ than non-impaired MS peers. They are more likely to be involved in accidents, including motor vehicle crashes. ${ }^{7-9}$ Difficulties in learning and remembering new information are the most prevalent cognitive deficits in MS. ${ }^{10}$ Cognitive impairment can be detected at early stage of MS, occurs in all disease subtypes and tends to progress

\footnotetext{
From the Department of Neurology (VS, FA, NZ), Department of Psychiatry (HAZ), Medical School; Department of Epidemiology and Biostatistics (MJ), School of Public Health, Isfahan University of Medical Sciences, Isfahan, Iran.

Received December 17, 2007. Final Revisions Submitted March 31, 2008. Correspondence to: M. Janghorbani, Department of Epidemiology and Biostatistics, School of Public Health, Isfahan University of Medical Sciences, Isfahan, Iran.
} 
over time. ${ }^{2}$ Since treatment cognitive impairment can improve quality of life and outcome, the treatment of cognitive decline in MS is justified as an important goal.

Very little is known about effective treatments for cognitive impairment in MS. The most frequently used drugs are diseasemodifying agents, including interferon beta- $1 b^{11,12}$ glatiramer acetate, ${ }^{13}$ interferon beta- $1 \mathrm{a} ;{ }^{14}$ symptomatic agents for fatigue; ${ }^{15,16}$ and acetylcholinesterase inhibitors (AchEI). ${ }^{10,17,18}$

Donepezil, galantamine, and rivastigmine are the three AchEIs most widely used to treat Alzheimer's disease. ${ }^{19,20}$ Donepezil and galantamine as well as physostigmine have recently been tested in other cognitive disorders, including MS. ${ }^{17,18,21-25}$ These reports ${ }^{18,21-25}$ suggest that AchEI drugs may be effective as an adjunctive therapy for treatment of cognitive decline in MS. It is hypothesized that MS cholinergic deficits might derive from disruption of cholinergic pathways and impaired axonal transport of acetylcholine due to demylination and axonal transaction. ${ }^{26}$ Additional mechanisms of action may include increases in cerebral glucose utilization. Though the currently used AchEI have the same treatment indication they differ pharmacologically. ${ }^{27}$ Rivastigmine induces a slowreversible inhibition of both AchEI and butyrylcholinestrase (BuChE), that is sustained for at least 12 months of repeated administration. ${ }^{28}$ Metabolism of rivastigmine occurs by its target enzymes (AchEI and BuChE), independent of hepatic drug metabolism cytochrome enzyme. No studies are available assessing effectiveness of rivastigmine in treatment of cognitive dysfunction in MS.

In the present study we evaluated the effect of rivastigmine in the treatment of cognitive dysfunction in MS.

\section{Patients And Methods}

This is a single-center randomized double-blind clinical trial to compare the efficacy of rivastigmine and placebo on cognitive impairment in MS patients.

Patients. Sixty patients who sought treatment for MS at our neurology clinic in Al-Zahra Hospital affiliated to Isfahan University of Medical Sciences, Iran, between October 2005 and February 2007 were evaluated. Entry criteria included men and women 15-55 years with a clinical or laboratory-supported diagnosis of definite MS (19 relapsing-remitting, 31 secondary progressive, and 10 primary progressive; mean standard deviation (SD) duration 5.4 (3.8) years, range 1-18 years), ${ }^{29}$ stable neurological functioning for at least one month prior to study entry and have an Expanded Disability Status Scale $(\text { EDSS })^{30}$ score $\leq 6$ and a willingness to continue current medications for the duration of the study. All patients were interviewed and tested neuropsychologically using the Wechsler Memory Scales (WMS), a standard clinical assessment procedure consisting of seven sub-tests that result is a summary score. ${ }^{31}$ The WMS was chosen because it assesses cognitive processes that are most commonly impaired in MS and translated and validated in Farsi. The test assesses several neuropsychological functions aside from sustained attention including speed of information processing, speed of information retrieval from memory stores, working memory and dual processing. All patients displayed at least mild verbal memory impairment as indicated by a WMS. "Concurrent antidepressants, antispasticity agents, anticholinergic drugs frequently taken for urinary problems, and disease-modifying therapies were permitted, as long as dosage had been constant for at least one month prior to the evaluation. Patients currently taking benzodiazepines were excluded, as these medications may affect cognition". ${ }^{18}$ Other exclusion criteria included current alcohol or substance abuse, history of head injury, or other medical condition known to affect cognition. Women of childbearing potential had to practice a clinically accepted method of contraception. Project was approved by institutional ethical committee and adequate informed consent obtained.

Randomization Scheme. A total of 71 patients were eligible for the study. Eleven patients were excluded because they refused entry. Sixty patients (27 (43.5\%) men, 33 (53.2\%) women) completed their treatment without interruption and were assigned randomly and equally to one of the two self-administer treatment groups. Patients were randomized according to a preexisting list produced by a computer program that differed from a random number generator only in that it assigned equal numbers of patients into each treatment group. The first treatment group received rivastigmine (registered trade name of Exelon, Novartis Pharma AG, Basle, Switzerland) $1.5 \mathrm{mg}$ once daily increment over 4 weeks to $3 \mathrm{mg}$ twice daily for a total of 12 weeks. The second group received placebo for 12 weeks. Patients were instructed to take their medication with or shortly after food. The hospital pharmacist was informed of all randomization assignments and was responsible for labeling the study drug and maintaining a master list linking the patients and their treatment assignments. In the month preceding the trial, all patients had a pre-treatment evaluation that consisted of obtaining demographic data, complete neurologic and medical history, physical and neurologic examination, and previous treatment. The patients had a mean SD age of 32.5 (8.6) years (range 16 to 55 years). The patient allocation is shown in the Figure.

Patient evaluation. The trial was double-blinded in that both patient and physician who assessed the outcome were not aware of treatment type that the patient was received. The masking of

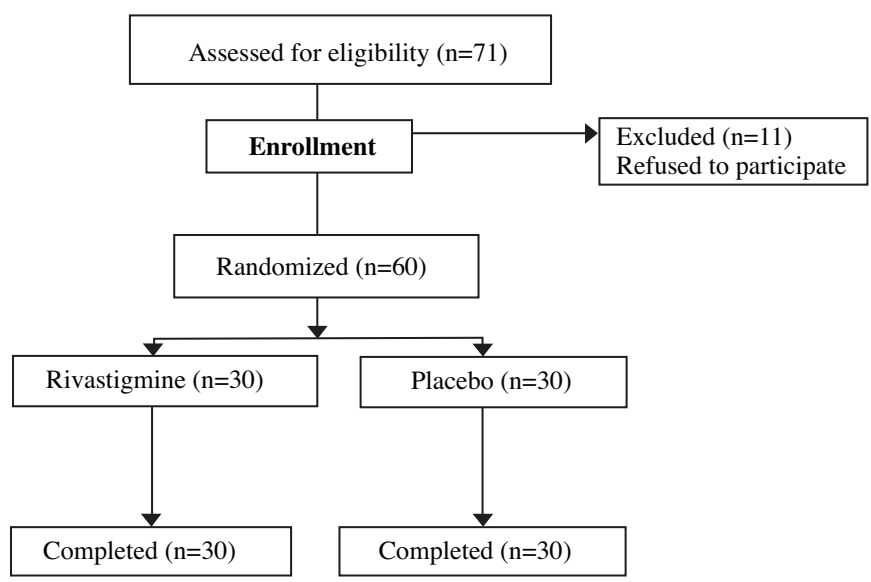

Figure: Design of the study. 
Table 1: Characteristics of patients by treatment group at baseline

\begin{tabular}{|c|c|c|c|}
\hline \multirow{2}{*}{ Characteristics } & \multicolumn{2}{|c|}{ Treatment group at baseline } & \multirow{2}{*}{$\begin{array}{c}\text { Differences } \\
(95 \% \mathrm{CI})\end{array}$} \\
\hline & $\begin{array}{c}\text { Rivastigmine }(\mathrm{N}=30) \\
\text { Mean (SD) }\end{array}$ & $\begin{array}{c}\text { Placebo }(\mathbf{N}=30) \\
\text { Mean (SD) }\end{array}$ & \\
\hline$\overline{\text { Age (years) }}$ & $33.4(9.6)$ & $31.6(7.6)$ & $1.8(-2.7,6.2)$ \\
\hline Duration of MS (years) & $6.3(4.1)$ & $4.5(3.2)$ & $1.8(-0.8,3.7)$ \\
\hline Expanded Disability Status Scale & $4.0(1.2)$ & $3.9(1.1)$ & $0.1(-0.5,0.7)$ \\
\hline \multicolumn{4}{|l|}{ Wechsler Memory Scale Subtests } \\
\hline Information & $5.6(0.6)$ & $5.8(0.4)$ & $-0.2(-0.4,0.1)$ \\
\hline Orientation & $4.9(0.3)$ & $4.9(0.3)$ & $0.0(-0.1,0.1)$ \\
\hline Mental control & $7.6(1.0)$ & $7.2(1.0)$ & $0.4(-0.1,0.9)$ \\
\hline Logical memory & $16.1(1.8)$ & $15.2(2.5)$ & $0.9(-0.2,2.0)$ \\
\hline Digit span & $4.6(0.7)$ & $5.0(1.0)$ & $-0.9(-1.3,-0.5)^{* * *}$ \\
\hline Visual reproduction & $8.1(1.0)$ & $9.7(1.4)$ & $-1.6(-.2 .2,-1.0)^{* * *}$ \\
\hline Associative learning & $13.0(2.8)$ & $12.0(2.0)$ & $1.0(-0.3,2.2)$ \\
\hline \multirow[t]{2}{*}{ General memory score } & $60.0(4.2)$ & $60.5(4.9)$ & $-0.5(-2.9,1.9)$ \\
\hline & No. $(\%)$ & No. $(\%)$ & \\
\hline \multicolumn{4}{|l|}{ Gender } \\
\hline Men & $15(50.0)$ & $12(40.0)$ & $10.0(-15.0,35.0)$ \\
\hline Women & $15(50.0)$ & $18(60.0)$ & - \\
\hline \multicolumn{4}{|l|}{ Education } \\
\hline Primary or below & $11(36.7)$ & $7(23.3)$ & $13.3(-9.6,36.3)$ \\
\hline Secondary & $11(36.7)$ & $13(43.3)$ & $6.7(-31.4,18.1)$ \\
\hline post-secondary & $8(26.7)$ & $10(33.3)$ & $-6.7(-29.8,16.5)$ \\
\hline \multicolumn{4}{|l|}{ Marital status } \\
\hline Married & $19(63.3)$ & $19(63.3)$ & $0.0(-24.4,24.4)$ \\
\hline Single & $11(36.7)$ & $11(36.7)$ & - \\
\hline \multicolumn{4}{|l|}{ MS subtypes } \\
\hline Relapsing-remitting & $9(30.0)$ & $11(36.7)$ & $-6.7(-30.5,17.1)$ \\
\hline Secondary progressive & $15(50.0)$ & $16(53.3)$ & $-3.3(-28.6,21.9)$ \\
\hline Primary progressive & $6(20.0)$ & $3(10.0)$ & $10.0(-7.9,27.9)$ \\
\hline \multicolumn{4}{|l|}{ Concomitant medications } \\
\hline Interferon beta & $19(63.3)$ & $22(73.3)$ & $-10.0(-33.4,13.4)$ \\
\hline Antidepressant & $25(83.3)$ & $29(96.7)$ & $-13.3(-28.1,1.5)$ \\
\hline Bladder drug & $19(63.3)$ & $19(63.3)$ & $0.0(-24.4,24.4)$ \\
\hline Antispasmodic & $22(73.3)$ & $20(66.7)$ & $6.7(-16.5,29.8)$ \\
\hline
\end{tabular}

$* \mathrm{P}<0.05, * * \mathrm{P}<0.01, * * * \mathrm{P}<0.001 . \mathrm{CI}=$ Confidence interval

the active and placebo treatments was preserved by creating treatments that looked identical. Patients were evaluated at baseline and 12 weeks after the start of the therapy by a qualified neurologist to evaluate the development of side effects of the medications, compliance of the patients, and efficacy parameters. Assessment of the course of the disease was done by change score in general memory score on the WMS (week 12 to week 0). Efficacy assessments of all patients were administered by a single rater (NZ) in the same sequence, and did not know which patients had received which treatment.

Statistical analysis. On the basis of previous estimates of standard deviation of recall change score $0.9,22$ we calculated that 30 patients per treatment group would be required to provide the study with 90 percent power to detect (with a two-sided alpha of 0.05 ) a mean difference in general memory score on the WMS from baseline of 2.5. Statistical analysis was based on an intention-to-treat principle. Comparison between groups receiving rivastigmine and placebo was made using Student's ttest for independent samples; comparisons between before and 12 weeks after treatment within each group were done by paired student's t test. Comparisons between proportions were done by chi-square or Fisher's exact test. Results are expressed as mean (SD) and $\mathrm{P}<0.05$ was considered statistically significant. All statistical tests were two-sided. The analyses were done on a personal computer using SPSS for Windows (SPSS Inc., Chicago, IL, USA). There was no interim analysis of treatment effects. 
Table 2: Comparison of Wechsler Memory Scale and its subtests in 60 multiple sclerosis patients before and after treatment with rivastigmine and placebo

\begin{tabular}{l|llllll}
\hline \multirow{2}{*}{ Wechsler Memory Scale } & \multicolumn{3}{c}{$\begin{array}{c}\text { Rivastigmine }(\mathbf{n = 3 0} \\
\text { Mean (SD) }\end{array}$} & $\begin{array}{c}\text { Placebo (n=30) } \\
\text { Mean (SD) }\end{array}$ \\
\cline { 2 - 6 } & At baseline & After therapy & Differences (95\% CI) & At baseline & After therapy & Differences (95\% CI) \\
\hline General memory score & $60.0(4.2)$ & $64.9(5.3)$ & $4.9(3.8,6.0)^{* * *}$ & $60.5(4.9)$ & $64.5(3.7)$ & $4.0(3.0,5.0)^{* * *}$ \\
Information & $5.6(0.6)$ & $5.6(0.6)$ & $0.0(-0.2,0.2)$ & $5.8(0.4)$ & $6.0(0.2)$ & $0.2(0.05,0.4)^{*}$ \\
Orientation & $4.9(0.3)$ & $4.9(0.3)$ & $0.0(-0.1,0.1)$ & $4.9(0.3)$ & $5.0(0.0)$ & $0.1(-0.03,0.2)$ \\
Mental control & $7.6(1.0)$ & $7.6(1.0)$ & $0.0(-0.4,0.4)$ & $7.2(1.0)$ & $8.0(1.0)$ & $0.8(0.5,1.2)^{* * *}$ \\
Logical memory & $16.1(1.8)$ & $18.0(2.0)$ & $1.9(1.4,2.4)^{* * *}$ & $15.2(2.5)$ & $16.4(2.5)$ & $1.2(0.7,1.7)^{* * *}$ \\
Digit span & $4.6(0.7)$ & $4.6(0.7)$ & $0.0(-0.3,0.3)$ & $5.5(1.0)$ & $5.9(0.9)$ & $0.4(0.2,0.5)^{* *}$ \\
Visual reproduction & $8.1(1.0)$ & $8.1(1.0)$ & $0.0(-0.4,0.4)$ & $9.7(1.4)$ & $10.1(1.5)$ & $0.4(0.1,0.6)^{* *}$ \\
Associative learning & $13.0(2.8)$ & $16.0(3.5)$ & $3.0(2.4,3.7)^{* * *}$ & $12.0(2.0)$ & $12.9(1.8)$ & $0.9(0.5,1.2)^{* * *}$ \\
\hline
\end{tabular}

$* \mathrm{P}<0.05, * * \mathrm{P}<0.01, * * * \mathrm{P}<0.001 . \mathrm{CI}=$ Confidence interval

\section{RESULTS}

Sixty patients who met the entry criteria were enrolled for the study. Patient compliance was good. The 60 patients who completed treatment were available for follow-up at 12 weeks. The two treatment groups were generally well matched at baseline with regard to age, gender, duration of MS, EDSS, the WMS general memory score and other MS characteristics. With respect to memory, rivastigmine group scored slightly but significantly lower on subtests of digit span and visual reproduction $(\mathrm{P}<0.001)$. The mean $(\mathrm{SD})$ age of rivastigmine and placebo groups were 33.4 (9.6) and 31.6 (7.6) years, respectively. The mean (SD) general memory score on the WMS at the start of treatment with rivastigmine and placebo was 60.0 (4.2) and 60.5 (4.9), respectively. Mean (SD) EDSS at the start of treatment with rivastigmine and placebo was 4.0 (1.2) and 3.9 (1.1), respectively. There was no statistically significant difference between them (Table 1). Rivastigmine treatment was well tolerated, with mild transient side effects that did not lead to dropout. The most common side effects associated with rivastigmine was nausea (six patients), dyspepsia (five patients), anorexia (five patients), dizziness (two patients), headache (two patients), tremor (one patient), anxiety (three patients), and confusion (one patient), appeared at the starting dose and at every increase of the dosage, but disappeared after the first month of treatment. Changes of mean general memory score on the WMS and its subtests before and after receiving rivastigmine or placebo are shown in Table 2. In both groups, the average WMS general memory score, as well as, on the subtests of logical memory and associative learning significantly increased. In placebo group, the mean WMS on subtests of information, mental control, digit span, and visual reproduction also increased. The average WMS general memory score increased from baseline by $4.9(95 \% \mathrm{CI} ; 3.8,6.0)$ in rivastigmine, compared to an increase of $4.0(95 \% \mathrm{CI} ; 3.0,5.0)$ in placebo group.

The average general memory score on the WMS at the end of trial did not change between rivastigmine and placebo group (mean difference, $0.4 ; 95 \% \mathrm{CI},-2.0,2.8$,). With respect to subtests on the WMS, rivastigmine group scored significantly lower on the subtests of information $(\mathrm{P}<0.01)$, mental control $(\mathrm{P}<0.001)$, digit span $(\mathrm{P}<0.001)$, and visual reproduction than placebo group $(\mathrm{P}<0.001)$, but scored higher on logical memory $(\mathrm{P}<0.05)$, and associative learning $(\mathrm{P}<0.001)$ (Table 3).

\section{Discussion}

In the current study, the rivastigmine and placebo group were similar in memory abilities, measured by WMS general memory score. We found significant differences in WMS subtests of digit span and visual reproduction at baseline, and information, mental control, logical memory, digit span, visual reproduction and associative learning at the end of the trial between rivastigmine and the placebo group. To the best of our knowledge, no other studies are available comparing the effect of rivastigmine with placebo on cognitive dysfunction in MS. No unusual or unexpected safety risks were found with rivastigmine therapy in this population with MS. The spectrum of most frequent adverse events is similar to previous studies that have been reported with rivastigmine, with gastrointestinal cholinergic side effects being most common. Earlier studies of AchEI in MS showed promising results, despite the fact that these studies suffer from several methodological limitations. Earlier studies showed that donepezil improved memory in MS. ${ }^{18,22,24}$ A double-blind placebo-controlled trial of four patients found an improvement in verbal memory with IV injection of physostigmine versus placebo. ${ }^{21}$ Another doubleblind, placebo-controlled study of eight memory-impaired patients given oral physostigmine also resulted in a significant improvement in cognition, as measured by verbal memory. ${ }^{23}$ Disease-modifying agents, including interferon beta- $1 b,{ }^{11,12}$ glatiramer acetate, ${ }^{13}$ interferon beta- $1 \mathrm{a} ;{ }^{14}$ and symptomatic agents for fatigue, ${ }^{15,16}$ also have been reported in controlled studies to have efficacy for improving memory and cognition. The mechanisms of action of those medications that have been proven effective in cognitive decline are varied. ${ }^{32}$ The beneficial effects of disease-modifying drugs may occur in the short term due to the anti-inflammatory effects of the therapy, and in the long-term due to the protective effects on tissue damage in the brain. In particular, disease-modifying drugs, such as beta- 
Table 3: Comparison of Wechsler Memory Scale and its subtests in 60 multiple sclerosis patients three months after treatment with rivastigmine and placebo

\begin{tabular}{|c|c|c|c|}
\hline \multirow[t]{2}{*}{ Wechsler Memory Scale } & \multicolumn{2}{|c|}{ Treatment group at three months } & \multirow{2}{*}{$\begin{array}{l}\text { Differences } \\
(95 \% \mathrm{CI})\end{array}$} \\
\hline & $\begin{array}{c}\text { Rivastigmine (N=30) } \\
\text { Mean (SD) }\end{array}$ & $\begin{array}{c}\text { Placebo }(\mathbf{N}=30) \\
\text { Mean (SD) } \\
\end{array}$ & \\
\hline Genera & $64.9(5.3)$ & $64.5(3.7)$ & $0.4(-2.0,2.8)$ \\
\hline Info & $5.6(0.6)$ & $6.0(0.2)$ & $-0.4(-0.6,-0.1)^{*}$ \\
\hline Orientation & $4.9(0.3)$ & $5.0(0.0)$ & $-0.1(-0.2,0.03)$ \\
\hline Mental control & $7.6(1.0)$ & $8.0(1.0)$ & $-0.4(-0.9,0.1)$ \\
\hline Logical memory & $18.0(2.0)$ & $16.4(2.5)$ & $1.6(0.4,2.8)^{*}$ \\
\hline Digit span & $4.6(0.7)$ & $5.9(0.9)$ & $-1.3(-1.7,-0.9)^{* *}$ \\
\hline Visual reprc & $8.1(1.0)$ & $10.1(1.5)$ & $-2.0(-2.7,-1.3)^{* *}$ \\
\hline Associative learning & $16.0(3.5)$ & $12.9(1.8)$ & $3.1(1.7,4.6)^{* *}$ \\
\hline
\end{tabular}

$* \mathrm{P}<0.05, * * \mathrm{P}<0.01, * * * \mathrm{P}<0.001 . \mathrm{CI}=$ Confidence interval

interferons and glatiramer acetate, may prevent or reduce the progression of cognitive dysfunction by containing the development of new cerebral lesions or by reducing the progression of brain atrophy. Assessment of neuropsychological outcomes in trials of disease-modifying agents is a recent phenomenon and preliminary data comes from pivotal trials on interferon beta- $1 b,,^{11,12,33}$ interferon beta- $1 a^{14,34}$ and glatiramer acetate. ${ }^{13}$ Most trials on symptomatic agents have focused on therapies for fatigue. Fatigue is a common symptom in MS, and it is often associated with impairment of cognitive performance due to reduction of glucose metabolism in the brain. ${ }^{15,16,35}$ As suggested by Krupp et al, ${ }^{18}$ in MS, cholinergic deficits might derive from disruption of cholinergic pathways and impaired axonal transport of acetylcholine due to demyelination and axonal transaction. Additional mechanisms of action may include increases in cerebral glucose utilization.

This trial could draw criticism because of the short follow-up. A 12-week follow-up, rather than 24 weeks as in the donepezil trial by Krupp et $\mathrm{al}^{18}$ may be too short to appreciate the real impact of the therapy. Assessing the efficacy in the longer-term period is therefore warranted. Another limitation is the low dose of rivastigmine. In patients with Alzheimer's disease, rivastigmine is usually started with $1.5 \mathrm{mg}$ twice a day, gradually increased, up to $6 \mathrm{mg}$ twice a day. However, the randomized controlled trials of 24 weeks of rivastigmine reported discontinuation rates in the range of $35 \%$ in patients receiving rivastigmine at $6-12 \mathrm{mg} /$ day. $^{36,37}$ A total daily $3 \mathrm{mg}$ of rivastigmine is probably not enough to show its efficacy on cognition. In the Krupp et al study, ${ }^{18}$ patients with MS were treated with donepezil starting from $5 \mathrm{mg}$ to full dose of $10 \mathrm{mg}$. Other limitations include the use of a relatively small sample of patients tested at a single study site. The present results clearly need to be replicated and extended across multiple centers and investigators in a larger scale trial, with a longer duration of follow-up and higher dose of rivastigmine. With respect to memory, the rivastigmine group scored slightly lower on subtests of digit span and visual reproduction at baseline. These differences persisted at the end of the trial. Functional MRI was not available to our center nor was appropriate software to calculate burden lesions of brain and brain volume and hence we are unable to describe them. However, in almost all patients, conventional MRI data (i.e. plaque volume, plaque localization and brain atrophy) were compared with neuropsychological test scores (WMS) to relate structural lesions to cognitive function.

In conclusion, the study did not show any significant beneficial effect of rivastigmine, although results are not conclusive due to above mentioned limitations. It is also to be noted that the improvement of WMS performance in both the placebo and rivastigmine group is probably due to unspecific "practice effect", a well known phenomenon in neuropsychological testing.

\section{REFERENCES}

1. Bobholz JA, Rao SM. Cognitive dysfunction in multiple sclerosis: a review of recent developments. Curr Opin Neurol. 2003; 16(3):283-8.

2. Amato MP, Ponziani G, Siracusa G, Sorbi S. Cognitive dysfunction in early-onset multiple sclerosis: a reappraisal after 10 years. Arch Neurol. 2001; 58(10):1602-6.

3. Amato MP, Ponziani G, Pracucci G, Bracco L, Siracusa G, Amaducci L. Cognitive impairment in early-onset multiple sclerosis. Pattern, predictors, and impact on everyday life in a 4year follow-up. Arch Neurol. 1995; 52(2):168-72.

4. Rao SM, Leo GJ, Ellington L, Nauertz T, Bernardin L, Unverzagt F. Cognitive dysfunction in multiple sclerosis. II. Impact on employment and social functioning. Neurology. 1991; 41(5): 692-6.

5. Wild KV, Lezak MD, Whitman RH, Bourdette DN. Psychosocial impact of cognitive impairment in the multiple sclerosis patient. J Clin Exp Neuropsychol. 1991; 13:74.

6. Beatty WW, Blanco CR, Wilbanks SL, Paul RH, Hames KA. Demographic, clinical, and cognitive characteristics of multiple sclerosis patients who continue to work. J Neurol Rehabil. 1995; 9:167-73.

7. Schultheis MT, Garay E, Millis SR, Deluca J. Motor vehicle crashes and violations among drivers with multiple sclerosis. Arch Phys Med Rehabil. 2002; 83(8):1175-8.

8. Schultheis MT, Garay E, Deluca J. The influence of cognitive impairment on driving performance in multiple sclerosis. Neurology. 2001; 56(8):1089-94. 
9. Fischer JS. Assessment of neuropsychological function. In: Rudick RA, Goodkin DE, editors. Multiple sclerosis therapeutics. London: Martin Dunitz; 1999. p. 31-47.

10. Amato MP, Portaccio E, Zipoli V. Are there protective treatments for cognitive decline in MS? J Neur Sci. 2006; 245(1-2):183-6.

11. Pliskin NH, Hamer DP, Goldstein DS, Towle VL, Reder AT, Noronha A, et al. Improved delayed visual reproduction test performance in multiple sclerosis patients receiving interferon beta-1b. Neurology. 1996; 47(6):1463-8.

12. Barak Y, Achiron A. Effect of interferon-beta- $1 \mathrm{~b}$ on cognitive functions in multiple sclerosis. Eur Neurol. 2002; 47(1):11-14.

13. Weinstein A, Schwid SR, Schiffer RB, McDermott MP, Giang DW, Goodman AD. Neuropsychologic status in multiple sclerosis after treatment with glatiramer. Arch Neurol. 1999; 56(3): $319-24$.

14. Fischer JS, Priore RL, Jacobs LD, Cookfair DL, Rudick RA, Herndon RM, et al. Neuropsychological effects of interferon beta-1a in relapsing multiple sclerosis. Multiple Sclerosis Collaborative Research Group. Ann Neurol. 2000; 48(6): 885-92.

15. Cohen RA, Fisher M. Amantadine treatment of fatigue associated with multiple sclerosis. Arch Neurol. 1989; 46(6):676-80.

16. Geisler MW, Sliwinski M, Coyle PK, Masur DM, Doscher C, Krupp LB. The effects of amantadine and pemoline on cognitive functioning in multiple sclerosis. Arch Neurol. 1996; 53(2): $185-8$.

17. Amato MP. Donepezil for memory impairment in multiple sclerosis. Lancet Neurol. 2005; 4(2):72-3.

18. Krupp LB, Christodoulou C, Melville P, Scherl WF, MacAllister WS, Elkins LE. Donepezil improved memory in multiple sclerosis in a randomized clinical trial. Neurology. 2004; 63(9):1579-85.

19. Evans JG, Wilcock G, Birks J. Evidence-based pharmacotherapy of Alzheimer's disease. Int J Neuropsychopharmacol. 2004; 7(3): 351-69.

20. Birks JS, Harvey R. Donepezil for dementia due to Alzheimer's disease. Cochrane Database Syst Rev. 2003 (3) CD001190.

21. Leo GJ, Rao SM. Effects of intravenous physostigmine and lecithin on memory in multiple sclerosis: report of a pilot study. J Neurol Rehabil. 1988; 2:123-9.

22. Christodoulou C, Melville P, Scherl WF, Macallister WS, Elkins LE, Krupp LB. Effects of donepezil on memory and cognition in multiple sclerosis. J Neurol Sci. 2006; 245(1-2):127-36.

23. Unverzgagt FW, Rao SM, Antuono PG. Oral physostigmine in the treatment of memory loss in multiple sclerosis (MS). J Clin Exp Neuropsychol. 1991; 13:74.

24. Krupp LB, Elkins LE, Scheffer S, Smiroldo J, Coyle PK1. Donepezil for the treatment of memory impairments in multiple sclerosis. Neurology. 1999; 52 Suppl. 2: A137.
25. Greene YM, Tariot PN, Wishart H, Cox C, Holt CJ, Schwid S, et al. A 12-week, open trial of donepezil hydrochloride in patients with multiple sclerosis and associated cognitive impairments. J Clin Psychopharmacol. 2000; 20(3):350-6.

26. Ruberg M, Villageois A, Bonnet AM, Rieger F, Agid Y, Fahn S. Acetyl cholinesterase and butyrylcholinesterase activity in the cerebrospinal fluid of patients with neurodegenerative diseases involving cholinergic systems. J Neurol Neurosurg Psychiatry. 1987; 50(5):538-43.

27. Brufani M, Filocamo L. Rational design of cholinesterase inhibitors. In: Giacobini E, editor. Cholineterase and cholinesterase inhibitors. London: Martin Dunitz; 2000.

28. Darreh-Shori T, Almkvist O, Guan ZZ, Garlind A, Strandberg B, Svensson AL, et al. Sustained cholinesterase inhibition in AD patients receiving rivastigmine for 12 months. Neurology. 2002; 59(4):563-72.

29. Poser CM, Paty DW, Scheinberg L, McDonald WI, Davis FA, Ebers $\mathrm{GC}$, et al. New diagnostic criteria for multiple sclerosis: guideline for research protocols. Ann Neurol. 1983; 13(3): 227-31.

30. Kurtzke JF. Rating neurologic impairment in multiple sclerosis: an expanded disability status scale (EDSS). Neurology. 1983; 33(11):1444-52.

31. Wechsler D. Wechsler memory scale (3rd ed. (WAIS-III)). New York: Psychological Corporation; 1998

32. Rao SM, Leo GJ, Bernardin L, Unverzagt F. Cognitive dysfunction in multiple sclerosis. I. Frequency, patterns, and prediction. Neurology. 1991; 41(5):685-91.

33. Interferon beta- $1 \mathrm{~b}$ is effective in relapsing-remitting multiple sclerosis. I. Clinical results of a multicenter, randomized, doubleblind, placebo-controlled trial. The IFNB Multiple Sclerosis Study Group. Neurology. 1993; 43(4):655-61.

34. Jacobs LD, Cookfair DL, Rudick RA, Herndon RM, Richert JR, Salazar AM, et al. Intramuscular interferon beta-1a for disease progression in relapsing multiple sclerosis. The Multiple Sclerosis Collaborative Research Group (MSCRG). Ann Neurol. 1996; 39(3):285-94.

35. Bakshi R. Fatigue associated with multiple sclerosis: diagnosis, impact and management. Mult Scler. 2003; 9(3):219-27.

36. Corey-Bloom J, Anand R, Veach J; for the ENA 713 B352 Study Group. A randomized trial evaluating efficacy and safety of ENA 713 (rivastigmine tartrate), a new acetylcholinesterase inhibitor, in patients with mild to moderately severe Alzheimer's disease. Int J Geriatr Psychopharmacol. 1998; 1:55-65.

37. Rösler M, Anand R, Cicin-Sain A, Gauthier S, Agid Y, Dal-Bianco $\mathrm{P}$, et al. Efficacy and safety of rivastigmine in patients with Alzheimer's disease: international randomised controlled trial. BMJ. 1999; 318(7184):633-8. 